\title{
Corporate social responsibility: necessity to integrate into educational programs of economists and lawyers
}

\author{
Tatyana Savina ${ }^{1}$, Vladimir Filatov ${ }^{2 *}$, Victor Mishakov ${ }^{3}$, Svetlana Osipenko ${ }^{4}$, and Svetlana \\ Artemyeva $^{5}$ \\ ${ }^{1}$ National Research Ogarev Mordovia State University, Bolshevistskaya St., 68, 430005 Saransk, \\ Russia \\ ${ }^{2}$ Moscow State University of food production, Volokolamsk highway St., 11, 125080 Moscow, \\ Russia \\ ${ }^{3}$ The Kosygin State University of Russia, (Technology. Design. Art), Sadovnicheskaya St., 33/1, \\ 117997, Moscow, Russia \\ ${ }^{4}$ Military University of the Ministry of Defense of the Russian Federation, B. Sadovaya St., 14 \\ 123001, Moscow, Russia \\ ${ }^{5}$ K.G. Razumovsky Moscow State University of Technologies and Management (the First Cossack \\ University), Zemlyanoy Val St., 73 109004, Moscow, Russia
}

\begin{abstract}
The purpose of the study is to show the necessity to integrate the Corporate Social Responsibility course into the educational process. The methodological basis of the study are such methods of scientific knowledge as a historical method, method of logical unity of analysis and synthesis, systematic method, and others. The questions of necessity to reflect CSR in educational programs of economists training programs are discussed. The author substantiates the reasons for the growing interest in this issue. A review of relevant practices in the field of CSR knowledge dissemination is given. It was found that the introduction of the proposed educational product in the learning process allows to strengthen main vocational training programs in many areas of training, to improve their efficiency, to have a significant impact on improving the quality of students' knowledge, and contribute to the development and the formation of a fundamentally new professional competencies.
\end{abstract}

\section{Introduction}

The concept of long-term socio-economic development of the Russian Federation for the period up to 2030 defines the strategic goal of the state policy in the field of education as priority areas, increasing the availability of quality education that meets the requirements of innovative economic development, modern needs of society and every citizen. In practice, the implementation of "prolonged" reforms of the last decades, we can note a lack of consistency, continuity in the implementation of the national strategy of higher education

\footnotetext{
${ }^{*}$ Corresponding author: filatov_vl@mail.ru
} 
development in Russia, which led to "the blind", a fragmented copy of the Bologna system, focused on competent preparation and in-demand competitive specialists.

Global issues of corporate social responsibility (CSR) has become pressing for Russia as well. The urgency of the demand for this phenomenon is determined by the serious challenges from both the society and business environment. With an ever-existing social and economic uncertainty business environment fundamentally new and unique growth driver are necessary. Today in the business community strict awareness of the inevitable revision of key business principles clearly appeared. It is about building a unique business model capable of tackling socially significant tasks. In these conditions there is an objective necessity to understand the growing role of social responsibility on the part of the business community. We believe that foster a culture of socially responsible behavior should begin in universities. All fields marked emphasize the importance of ideas regarding CSR as a new business ideology to the widest audience of the training program of higher education. Solving this problem is possible through the integration of CSR issues into educational programs (EP) of higher education system.

Factors that indicate the" protracted nature "of the crisis in the Russian legal education system include: the policy of "permanent introduction" of new Federal state educational standards for higher professional education in the field of law; the continuity and continuity of the process of education of all educational programs between different levels of training; the rules for combining educational programs for different cycles of curricula in different universities; the shortage of highly qualified personnel; the decline in the quality and funding of basic scientific research, methodical and methodological work in law schools; in a qualifying plan in the sectors of the economy, the status of bachelor and master is not sufficiently defined (bachelor, his status in the higher education system is not regulated); providing methodology to determine the objectivity of the quality factor of the final certification of graduates of educational institutions; creating conditions for improving the quality of education and upbringing in educational institutions of all forms, types and kinds; issues of organization, planning of the educational process and optimization of management of training and control in higher education institutions.

As another argument confirming the relevance and necessity for CSR integration in higher education programs we can mention constantly growing attention to CSR which is observed mainly by the very business education. This positive trend is due to companies request to corporate social responsibility, on the one hand, and to advanced professionals capable of developing effective social strategy, create social innovations and implement them in practical activities of companies, as well as achieve stable social changes on the other hand.

A growing interest to corporate social responsibility issues is also observed by students themselves. This is confirmed by the facts obtained as a result of a personal survey. $75 \%$ of respondents said that they were familiar with the CSR phenomenon. Only $15 \%$ indicated that it is not bad / relatively good and know this concept; $60 \%$ chose the answer - "just heard about this phenomenon." At the same time $75 \%$ of the students expressed a desire to learn more about CSR. Another indication of the relevance of the course is the holding (in Moscow and St. Petersburg (2011), Saransk (2014) conferences, symposia, round-table talks where the problem of CSR teaching in Russian universities have been widely discussed. According to the overall assessment of the participants of the events in the majority universities CSR issues is not systematic and insufficient in the educational programs.

Under these conditions it is fair to believe that the foundations of CSR should be "grafted" to the young generation in universities. It allows novice business innovators with less losses and professionally competently promote their business ideas, achieve sustainable 
social changes, comply with the principles of business ethics and socially responsible culture.

\section{Materials and Methods}

Questions of socially responsible business behavior are the focus of many researches. Among foreign studies devoted to CSR issues it is necessary to highlight fundamental work Pava M.L. [1], Broberg M.P. [2], Robertson D.C.[3], Weinstein S.L.[4], Burke L. [5], Pava M.L.[6] and others. Questions relating to the conceptual foundations of the institutionalization of socially responsible governmental economy are covered in works of Garrison G. [7], Wulfson M. [8], Adebayo E. [9], M. Schwartz, A. Caroll [10], Englander E. [11].

Among Russian authors and researchers of the theory and practice of social development and institutional CSR reforms, sustainable development issues should be mentioned Blinova E.A. [12], Vertakova Yu. [13], Denisov I.V. [14], Simchenko N. [15], Savina T. [16], Shumilova A. [17], Soboleva I. [18], Zaitseva N. A. [19], Larionova A.A.[20] and others.

Among modern foreign studies specifically devoted to the problems of promoting CSR ideas in the market of educational services the works of Zieliński M. [21], Stoyanov Philip [22], J.M. Alcaraz [23] should be noted. Applied aspects responsible management education disclosed in works of Filho Arruda [24], L.Berényi and N. Deutsch [25]. Questions regarding management competence and business ethics are represented in the works of Melissen F. [26], Serbănescu C. [27].

The purpose of the study is to show the importance of promoting an educational product in the course "Corporate Social Responsibility" in the educational process. Objectives: to consider issues relating to necessity to include CSR into educational programs of economists; justify the reasons for the growing interest in this issue; summarize relevant practice aimed at increasing the knowledge about CSR. The methodological bases of the study are scientific methods of cognition (combination of historical and logical unity, conventional techniques of analysis and synthesis) and specific evaluation methods.

\section{Results and discussion}

Nowadays it is crucial and must take into account the factors contributing to the achievement of fast pace of technology development, especially socially important and actively implement such changes in educational programs. Training course "Corporate social responsibility" helps to solve this problem. The course meets all the requirements of new social order and is harmoniously integrated into the Concept of Development of Education of the Russian Federation up to 2020. Implementation of the proposed educational product in the learning process will strengthen the basic professional educational programs in many areas of training, increase their efficiency and will have a significant impact on improving the quality of knowledge of students.

In a number of Russian universities centers for monitoring and diagnosing CSR problems have been formed as well as some positive experience in educational practice has been gained. Among them: GSOM SPbSU, Financial University under the Government of the Russian Federation, NRU - HSE, Faculty of Economics, St. Petersburg State University. Russian educational practices affecting CSR issues are broadcast on YouTube.com: "Social responsibility of business as an innovative strategy" (Blagov Yu.); Corporate social responsibility (Yakimets V.N.); National Conference "CSR - 2014/2015"; "CSR as a component of sustainable development"; CSR in a period of instability. How to 
fulfill our obligations?; Corporation and social development: responsibility, charity and innovations. V.N. Yakimets's Lecture The master's program "Corporate Governance and Business Responsibility" is implemented within in Tver State University.

Rich positive experience in integrating CSR issues is widely represented in foreign educational master's programs which are actively implemented in business schools «EABIS - The Academy of Business in Society" actively develop training courses on CSR.

The experience of the European Union in the promotion of educational programs Master and MBA training program CSR: CSR \& NGO-Management (MBA), Hochschule BonnRhein-Sieg (Germany); MBA + Master of Responsible Management; Master of Business Administration (MBA) in Finance and Responsible Investment, Sustainability Management School (Switzerland). Workshops on CSR: "CSR: how to build a profitable business, working responsibly", Kiev; Workshop on CSR for students of MGIMO; Workshop "CSR Practice", Minsk.

Course integration in the educational economists training program will contribute to socially responsible, active, creative personality able to solve the problem of socially significant nature and achieve sustainable social changes. In addition, it will open up wide opportunities for students to implement new social ideas and is aimed at promoting initiatives in the direction of CSR.

The project corresponds with educational standards according to which Mordovia State University carries out its educational activities. According to the Federal State Educational Standards of Higher Education in training program 38.04.01 Economics (Master Level) (Order of the Ministry of Education and Science of the Russian Federation No. 321 of March 30, 2015), the proposed project will allow students to develop as general cultural competencies (willingness to act in non-standard situations, bear social and ethical responsibility for accepted solutions (UC-2), a willingness to self-development, selfrealization, the use of the creative potential (UC-3), and develop professional competence according to professional activity. In the economic project it will develop professional competence PC-7 "ability to develop strategy of behavior of economic agents in various markets", in organization and management activity - PC-12 The project is based on the knowledge, skills, methods, activities and attitudes formed in the course of the study of the complex of disciplines provided by the curriculum of the master's program in training program 38.04.01 Economics, namely: Economics of enterprises and organizations (advanced level), Actual problems of entrepreneurship, management. In its turn the project will create the theoretical base necessary for the effective development of disciplines such as the Network Economy of Innovations, Segmentary Analysis of Business, Analysis and Assessment of Business

The purpose of the course is the formation of students' knowledge and skills in the field of CSR which will allow them to master new competencies regarding socially responsible behavior, rules of business etiquette and social culture of thinking.

We assume that this educational product will be presented to the system structure including the introduction, the main and additional parts.

Introduction section will assume that you have the following structural elements.

1. The purpose and objectives of the training course.

2. The place of the educational product in the structure of vocational training programs

3. Student competency map.

The structure of the main part.

1. Lectures (hourly plan, detailed topics of lecture material).

2. A detailed plan of seminars, including various types of individual tasks (case studies, tests, etc.).

3. Assessment including tests, case studies, business games, etc.

The structure of the additional part. 
1. Round table "The policy of relations between business, society and government: foreign practice and Russian realities."

2. Workshop "CSR is a new ideology of business."

3. Training "CSR as a long-term trend."

The process of implementing the educational product is possible due to modern training techniques. Each student must create an e-portfolio, which is a set of documents with works done in the process of the course. The process of realization of an educational product can be carried out in 4 stages.

1. Preparatory. Approval of the program of the course; development and posting test (about 40 tasks) in the Moodle system is at this stage. A student questionnaire, presentations of lectures and cases will be developed.

2. Educational. The goal is to form basic knowledge and skills in the field of CSR among students. At this stage the process of implementation of the educational product in educational activities will be carried out. A lecture course will be given, seminars will be held. Frequency of classes is once every two weeks.

3. Scientific research. The goal is to form students' competence in the ability to effectively, efficiently and successfully apply creative research and leaders qualities; At this stage we prepare and publish scientific articles.

4. Practically oriented stage.

This stage involves:

1. Round-table talk "Policy of business relationships with society and government : foreign practice and Russian reality". The goal is to exchange views with the target audience of the stated problems which will develop the students' competence in the ability to take an active part in the solution of socially significant tasks and to achieve sustainable social change.

2. Workshop "CSR is a new ideology of business." The goal is to build students' competence to promote unique social ideas and initiatives that stimulate CSR policies and skills for independent implementation of socially significant projects.

3. Training "CSR as a long-term trend". The goal is to develop among students the competencies of interpersonal and professional behavior in discussion and communication.

The educational product implementation process will be carried out using modern educational technologies. Each student will be required to create an e-portfolio, which is a set of documents with works done during the course.

The main criterion for evaluating the success of the course is to monitor and knowledge quality control by score-rating system during the course (max -100 points of the course, min-55). Student performance for each type of work will be reflected in the electronic educational environment of the university.

New technology to evaluate the success of the implementation and promotion of the project will serve as a listener questionnaire sheet as feedback that allows you to assess the success of the project with the help of the participants.

An obligatory criterion for assessing success is the presence of a student's portfolio as a means of assessing the quality of educational achievements, collection of papers done during the project. The purpose of creating a portfolio is to collect and take into account the results obtained during the course.

The integration of the course in the educational process will be based on new approaches and teaching methods that will increase the attractiveness of the proposed course. The course provides students participate in professional trainings and business games, elaboration of business cases, the use of interactive teaching methods, methods of problem and projective training, presentations, videos and research papers.

Let us single out the main approaches and methods on which the process of teaching the course will be built: 1) systematic method; 2) innovative approach; 3) causal approach; 4) 
exclusive approach; 5) simultaneous approach (making appropriate adjustments to the preparation and organization of training to meet the requirements of its adaptability to the Russian practice); 6) continuous approach (provides life-long learning).

The methodological novelty of the course is the presence of a student's electronic portfolio. Portfolio is a set of work done over a semester. The purpose of portfolio is to collect, monitor and take into account the results obtained during the implementation of the educational product. Using the portfolio will contribute to the dynamics and selfdevelopment of the learner, as well as transparency, system, cohesiveness and criteriabased assessment.

\section{Conclusions}

Thanks to the introduction of the course in the educational process the following results are possible.

1. Implementation of the course will integrate active creative individuals capable of participating in the decision of socially significant problems and achieve sustainable social changes.

2. Knowledge about CSR obtained in the course will increase academic mobility.

3. Students will master the level of corporate culture and business ethics practiced in foreign countries, mainly European.

4. Target groups will increase the level of socially responsible literacy and culture.

In addition, the course will contribute to the development and the formation of fundamentally new professional competencies:

1) the ability to effectively, efficiently and successfully apply creative, research and leadership skills;

2) the ability to develop social policies to create social innovations and implement innovative social technology;

3 ) the ability of young business innovators to apply the principles and criteria of social responsibility in the process of doing business;

4) the ability to promote unique social ideas and initiatives that stimulate CSR policies and independently implement socially significant projects.

The task of higher school teachers is to ensure that training is aimed at providing highquality educational process, at developing the personality of the student, the future specialist, his adaptation to the profession, to the social conditions of modern life. The most important component in the implementation of these tasks is the use of modern educational technologies in pedagogical practice.

\section{References}

1. M.L. Pava, J. Krausz, Journal of Business Ethics, 15(3) (1996)

2. M.P. Broberg, Journal of Business Ethics, 15(6) (1996)

3. D.C. Robertson, N. Nicholson, Journal of Business Ethics, 15(10) (1996)

4. S.L. Weinstein, Corporate social responsibility: how it is defined by occupational social workers and corporate leaders (1996)

5. L. Burke, J.M. Logsdon, Long Range Planning, 29(4) (1996)

6. M.L. Pava, J. Krausz, Journal of Business Ethics, 16(3) (1997)

7. Garrison G., Corporate social responsibility and the social audit (2004)

8. Wulfson M., Journal of Business Ethics, 29(1-2) (2001) 
9. E. Adebayo, Corporate social responsibility disclosure, corporate financial and social performance: an empirical analysis (2001)

10. M. Schwartz, A. Caroll, Business Ethics Quarterly, 4 (2003)

11. E. Englander, A. Kaufman, Enterprise \& Society, 5(3) (2004)

12. E.A. Blinova, M. Gregorić, E.A. Dedusenko, M.M. Romanova, European Research Studies Journal, 21(3) (2018)

13. Yu. Vertakova, V. Plotnikov, A. Chulakova. Corporate social responsibility: problems and prospects, International Multidisciplinary Scientific Conferences On Social Sciences And Arts SGEM 2014. Sofia, (2014)

14. I.V. Denisov, M.V. Khachaturyan, M.G. Umnova, Quality - Access to Success, 19(164) (2018)

15. N. Simchenko, E. Piskun, International Journal for Quality Research, 13(3) (2019)

16. T.N. Savina, Actual Problems of Economics, 184 (10) (2016)

17. A.A. Shumilova, National Interests: Priorities and Security, 9 (2014)

18. I. Soboleva, Questiomns on economics, 10 (2005)

19. N.A.Zaitseva, A.A.Larionova, A.S.Fadeev, V.V.Filatov, V.N.Zhenzhebir, T.S. Pshava, Eurasian Journal of Analytical Chemistry, 12 (2017)

20. A.A.Larionova, N.A.Zaitseva, A.S.Fadeev, V.N.Zhenzhebir, V.V.Filatov, T.S.Pshava, Eurasian Journal of Analytical Chemistry, 12 (2017)

21. M. Zieliński, I. Jonek-Kowalska, European Research Studies Journal, 23(2) 2020

22. Stoyanov Philip, Economy and Finance, 6 (2019)

23. J.M. Alcaraz, E. Thiruvattal, Academy of Learning Management and Education, 9(3) (2010)

24. Filho Arruda, International Journal of Management Education, 15(2) (2017)

25. L. Berényi, N. Deutsch, WSEAS Transactions on Business and Economics, 14 (2017)

26. F. Melissen, A.N. Mzembe, U. Idemudia, Y.Novakovic, Institutional Antecedents of the Corporate Social Responsibility Narrative in the Developing World Context: Implications for Sustainable Development Business Strategy and the Environment, 6 (2018)

27. C.Serbănescu, A.Vintilescu, Romanian Journal of Political Science,18(2) (2018) 